Jurnal Sentris KSMPMI Vol. 2 - 2019

\title{
Peran Indivindu dalam Dunia Internasional Studi Kasus: Upaya Nadia Murad, Sang Wanita Peraih Nobel Perdamaian Melawan Ketiranian ISIS
}

\author{
Venisa Yunita Sari \\ Prodi Ilmu Hubungan Internasional Universitas Tanjungpura
}

Email: venisari123@gmail.com

Nadia Murad Basee Taha adalah seorang aktivis Hak Asasi Manusia (HAM), peraih Nobel Perdamaian pada tahun 2018. Nadia Murad adalah salah satu korban dari kekejaman ISIS yang ditahan pada tahun 2014. Ia adalah satu dari sekitar 6.500 perempuan etnis Yazidi yang diperlakukan semena-mena oleh militan ISIS. Oleh karena itu, setelah bebas dari penyekapan ISIS, Nadia Murad gencar berkampanye memperjuangkan hak dari anak-anak maupun orang dewasa yang masih terbelenggu dalam cengkraman ISIS. Penelitian ini menggunakan teori feminisme yang kemudian didukung oleh kebijakan-kebijakan, nilai-nilai, norma maupun opini publik yang memiliki dampak terhadap kehidupan internasional. Penelitian ini kemudian merumuskan jawaban dari pertanyaan penelitian yang terkait dengan peranan individu dalam dunia internasional. Melalui pendekatan kualitatif dengan metode deskriptif, sumber data dalam tulisan ini berasal dari studi pustaka melalui telaah buku, artikel jurnal, dan laporan penelitian. Hasil tulisan ini terbagi menjadi dua poin penting dalam menjelaskan upaya Nadia Murad dalam memperjuangkan hak-hak minoritas di Irak agar terbebas dari belenggu ISIS. Pertama, latar belakang Nadia Murad. Kedua, peranan Nadia Murad memperjuangkan dan menyelamatkan masyarakat tahanan ISIS.

\section{Kata kunci: Nadia Murad, Nobel Perdamaian, Yazidi, ISIS}

\begin{abstract}
Nadia Murad Basee Taha is a Human Rights Activist, winner of the Nobel Peace Prize in 2018. Nadia Murad was one of the victims of ISIS-related atrocities in 2014. She is one of 6,500 Yazidi women who can be arbitrarily questioned by ISIS militia. Therefore, after being freed from ISIS incarceration, Nadia Murad have been vigorously campaigning to fight for both children and adults' rights, who were still shackled in the grip of ISIS. This study uses the theory of feminism which then supported by policies, values, norms, and public opinion that have an impact on international realm. This research then formulates answers to research questions relating to the role of individuals in the international world. Through qualitative with
\end{abstract}


Jurnal Sentris KSMPMI Vol. 2 - 2019

descriptive methods, the data sources in this paper come from literature studies by studying books, journals, and research reports. The results of this paper are divided into two important points in explaining the efforts of Nadia Murad in fighting for minority rights in Iraq to be free from the shackles of ISIS. First, Nadia Murad's background. Second, the role of Nadia Murad to fight for and save ISIS prisoners.

\section{Keywords: Nadia Murad, Nobel Peace Prize, Yazidi, ISIS}

\section{Pendahuluan}

Hak asasi manusia (HAM) adalah hak yang melekat pada setiap manusia dari sejak lahir tanpa memandang siapa manusia itu. Kemunculan konsep HAM sebagai sebuah isu penting bersamaan dengan perkembangan umat manusia yang mulai menyadari pentingnya pengakuan dalam menghormati dan mewujudkan kesetaraan umat manusia yang berdaulat dan utuh. Perkembangan HAM di dunia dimulai dengan dideklarasikannya piagam Magna Carta di Inggris pada tahun 1215 yang menjelaskan adanya larangan bagi raja untuk memungut pajak tanpa persetujuan tuan tanah. Selanjutnya pada 10 Desember 1948, Perserikatan BangsaBangsa (PBB) mengesahkan Deklarasi Universal Hak Asasi Manusia (DUHAM). Akan tetapi, deklarasi tersebut tidak bersifat mengikat dan tidak mempunyai kekuatan hukum yang mampu memaksa negara-negara penanda tangan untuk memenuhi isi DUHAM.

Pada tahun 1966, Komite Majelis Umum tentang HAM PBB mengesahkan dua kovenan, yaitu: Kovenan Internasional Hak Sipil dan Politik dan Kovenan Internasional Hak Ekonomi, Sosial, dan Budaya. Akan tetapi, kedua kovenan tersebut tidak cukup mengakomodir kebutuhan perempuan, selain itu juga belum adanya pengakuan tentang perbedaan perempuan dan laki-laki. Secara fisik, perempuan berbeda dengan laki-laki. Perempuan memiliki kerentanan khusus yang menjadikannya sering kali dianggap lebih lemah dari laki-laki. Sehingga tindakan-tindakan diskriminatif terhadap perempuan marak terjadi. Merespon diskriminasi tersebut, PBB membuat Deklarasi Penghapusan Diskriminasi terhadap Perempuan yang memuat persamaan hak dan kewajiban antara perempuan dengan laki-laki.

Banyaknya tindak diskriminasi dan kekerasan terhadap perempuan membuat para feminis bangkit unutk membela hak-hak kaum perempuan. Seperti pada kasus perbudakan yang dilakukan oleh militan ISIS terhadap kaum perempuan etnis Yazidi. ISIS tercatat telah membabat habis hak asasi wanita dengan menjadikan perempuan sebagai barang dagangan 
Jurnal Sentris KSMPMI Vol. 2 - 2019

yang di perjualbelikan di pasar-pasar gelap. Jika diidentifikasi kasusnya satu per satu, tentu akan sangat miris dan menyakitkan. Lima tahun yang lalu, seorang wanita bernama Nadia Murad Basee dari etnis Yazidi, selama tiga bulan disekap dan dijadikan pemuas seksual para militan ISIS. Dalam kesaksiannya yang disampaikan di banyak kesempatan, Nadia menceritakan bahwa dirinya diculik ISIS dan dibawa ke Mosul. Di Mosul, ia bertemu dengan ribuan wanita lain yang telah berada disana terlebih dahulu, yang sama-sama bernasib menjadi korban. Setelah terbebas dari penyekapan ISIS, kini perempuan peraih Nobel Perdamaian tersebut menjadi aktivis HAM untuk memperjuangkan hak-hak kaum Yazidi terhadap perbudakan ISIS.

Dalam konteks ini terlihat bahwa HAM dan feminisme memiliki hubungan yang saling berkaitan satu sama lain. Dinamika HAM telah mengantarkan kesadaran bahwa kelompokkelompok tertentu yang didiskriminasi dan ditindas rentan diabaikan dalam proses pembuatan sebuah kebijakan, khususnya mereka, kaum perempuan. Munculnya gerakan perempuan (feminis) telah menempatkan HAM sebagai salah satu ranah perjuangannya. Seperti yang dilakukan oleh Nadia Murad dalam mengkampanyekan aksi menuntut keadilan bagi korban kekerasan seksual yang dilakukan oleh ISIS. Nadia Murad merupakan salah satu contoh aktor non negara yang menyelesaikan isu-isu internasional. Aksi yang dilakukan oleh Nadia ini termasuk ke dalam salah satu gerakan aktivis beraliran feminisme.

\section{Kerangka Teori}

Feminisme adalah paham atau keyakinan bahwa perempuan merupakan bagian dari alam manusia, bukan dari yang lain yang menuntut kesetaraan dengan laki-laki dalam setiap aspek kehidupan, tanpa melihat kodrat dan fitrahnya. Kesetaraan ini biasanya disebut juga dengan istilah kesetaraan gender. ${ }^{1}$ Dalam hal kesetaraan gender dapat diartikan bahwa dengan adanya kesamaan kondisi laki-laki maupun perempuan dalam mendapatkan hak-haknya sebagai makhluk sosial atau manusia. Hal ini diharapkan agar mampu berperan dan berpatisipasi dalam semua kegiatan seperti politik, ekonomi, sosial, budaya, pendidikan serta kesamaan dalam menikmati pembangunan.

\footnotetext{
${ }^{1}$ Nuryati, 2015, "Feminisme dalam Kepemimpinan", Jurnal Universitas Islam Negeri (UIN) Raden Fatah Palembang, hlm: 162.

Diakses dalam http://jurnal.radenfatah.ac.id/index.php/istinbath/article/download/792/700/ pada 11 Mei 2019. ISSN 0216-5031

Copyright (? 2018 Universitas Katolik Parahyangan
} 
Jurnal Sentris KSMPMI Vol. 2 - 2019

Feminisme dalam HI muncul pada akhir 1900-an sebagai respon atas teori realisme. Sebagai gerakan sosial dan politk, feminisme bertujuan untuk mewujudkan kesetaraan lakilaki dan perempuan. ${ }^{2}$ Politik luar negeri suatu negara diibaratkan dengan maskulinitas, sifatsifat yang terkait dengan kelelakian, telah terjadi sejak dulu. Adanya kekerasan, keberanian, kekuasaan, kemandirian, bahkan kekuatan fisik sangat mempengaruhi pemikiran politik internasional. Budaya patriarki yang selalu memberi prioritas terhadap laki-laki mendorong terpeliharanya keyakinan ini. Sifat-sifat yang diasosiasikan dengan maskulinitas yang hegemonik diproyeksikan dalam tingkah laku negara, sehingga keberhasilan sebuah negara dalam berhubungan internasional cenderung diukur dengan kemampuannya dalam melindungi dirinya sendiri. Dalam klasifikasi "The Great Debate in International Relations", feminisme sering diletakkan dalam "Third Debate". 3

Menurut Manggi Humin, feminisme adalah sebuah ideologi pembebasan perempuan karena yang melekat dalam semua pendekatannya adalah keyakinan bahwa perempuan mengalami ketidakadilan karena jenis kelamin. Adapun menurut Mansour Fakih, feminisme adalah gerakan dan kesadaran yang bersumber dari asumsi bahwa kaum perempuan pada dasarnya ditindas dan dieksploitasi. Gerakan feminisme muncul dan berkembang dari sebuah ide yang diantaranya berupaya melakukan pembongkaran terhadap ideologi penindasan atas nama gender, pencarian akar ketertindasan perempuan, sampai upaya penciptaan pembebasan perempuan secara sejati. Feminisme adalah basis teori dari gerakan pembebasan perempuan. ${ }^{4}$

Sebagian feminis yang menganalisa hubungan internasional memulai dengan gender sebagai sebuah konstruksi sosial. ${ }^{5}$ Fokus analisa dan pertanyaan penelitian yang diajukan dalam penelitian feminis dalam Hubungan Internasional sangat berbeda dengan fokus dan pertanyaan penelitian dalam teori arus utama Hubungan Internasional. Feminis dalam Hubungan Internasional cenderung menggunakan tingkat analisa individu, sedangkan teori arus utama Hubungan Internasional cenderung menggunakan tingkat analisa negara bangsa. Feminis meneliti bagaimana konflik militer dan perilaku negara-negara dalam sistem internasional dikonstruksikan melalui hubungan struktur gender yang timpang sehingga memengaruhi individu. Secara tradisional, keamanan nasional selalu difokuskan secara

\footnotetext{
${ }^{2}$ Khasan Ashari, 2015, Kamus Hubungan Internasional, (Bandung: Nuansa Cendekia) hlm. 189.

${ }^{3}$ Nur Azizah, 2013, "Feminisme dalam Hubungan Internasional", Jurnal Diskusi Feminisme dalam

Hubungan Internasional. Diakses dalam http://hi.umy.ac.id/wp-content/uploads/2013/02/Nur-AzizahFeminisme-dalam-HI.pdf pada 11 Mei 2019.

${ }^{4}$ Nuryati, Op. Cit., hlm. 163.

${ }^{5}$ Nur Azizah, Op.Cit.
} 
Jurnal Sentris KSMPMI Vol. 2 - 2019

eksklusif pada keamanan militer. Feminis mengajukan konsep "keamanan bersama" untuk menggambarkan keamanan yang lebih komprehensif dan multidimensional dengan memperhatikan dimensi politik, ekonomi, dan lingkungan sosial sama pentingnya dengan dimensi militer.

\section{Pembahasan}

Pada saat berhasil menguasai wilayah teritorial Yazidi tahun 2014 lalu, kelompok ISIS dilaporkan berhasil menginvasi Kota Sinjar dan wilayah sekitarnya yang menjadi pusat populasi Yazidi. Sebagai konsekuensinya, 150.000 masyarakat Yazidi melarikan diri ke wilayah otonomi Kurdish, sementara ribuan yang lainnya terperangkap di Gunung Sinjar. Invasi ini juga disertai dengan bentuk kejahatan lainnya seperti pembunuhan, pemerkosaan, penghapusan identitas, perbudakan, pernikahan paksa, pemaksaan agama, serta perampasan harta benda. ${ }^{6}$ Yazidi merupakan etnis minoritas kuno di Irak bagian utara yang sejak lama menjadi korban persekusi. Dilansir dari The Independent bahwa Yazidi setidaknya sudah melewati 72 genosida sepanjang keberadaannya di Irak. Daerah pemukiman Yazidi ini berbatasan dengan Suriah dan agama mereka menggabungkan aspek-aspek Islam, Kristen, dan Yudaisme, di antara agama-agama lain. ${ }^{7}$

Kelompok pengawas hak asasi korban melaporkan cerita mengerikan mengenai perbudakan seksual dan eksekusi jika para wanitanya menolak masuk Islam Sunni atau tidak setuju menikah dengan anggota ISIS. ${ }^{8}$ Pemerintah Kurdistan yang menguasai kawasan Sinjar melaporkan bahwa hingga akhir Mei lalu, sedikitnya 3.275 warga Yazidi yang terdiri atas 2.083 wanita dan anak perempuan dan 1.292 pria, berhasil diselamatkan dari ISIS. ${ }^{9}$ Perbudakan besar terhadap perempuan dan gadis-gadis Yazidi dilatarbelakangi oleh adanya instruksi dan "pembenaran agama" oleh salah seorang pemimipin ISIS yaitu Turki Mubarak Abdullah

\footnotetext{
${ }^{6}$ Oriza Ardiyanti, 2019, "Perbudakan ISIS terhadap Perempuan Etnis Yazidi di Irak sebagai Kejahatan terhadap Kemanusiaan dalam Konflik Bersenjata", Jurnal Universitas Diponegoro, hlm. 990. Diakses dalam https://ejournal3.undip.ac.id/index.php/jihi/article/viewFile/22736/20789 pada 11 Mei 2019.

7 Novi Christiastuti, 2018, Ribuan Wanitia Yazidi Masih Jadi Budak Seks ISIS, diakses dalam https://news.detik.com/internasional/d-4149753/ribuan-wanita-yazidi-masih-jadi-budak-seks-isis pada 11 Mei 2019.

8 Fira Nursya'bani dan Esthi Maharani, 2016, Perempuan Yazidi Rencanakan Serangan Balas Dendam untuk ISIS, diakses dalam https://www.republika.co.id/berita/internasional/global/16/11/15/ogns8s335-perempuanyazidi-rencanakan-serangan-balas-dendam-untuk-isis pada 11 Mei 2019.

${ }^{9}$ Haris Fadhil, 2018, Kekejaman ISIS Jadikan Ribuan Wanita Yazidi Budak Seks, diakses dalam https://news.detik.com/internasional/d-4150014/kekejaman-isis-jadikan-ribuan-wanita-yazidi-budak-seks pada 11 Mei 2019.
} 
Jurnal Sentris KSMPMI Vol. 2 - 2019

Ahmad al-Binali yang merupakan penasehat penasihat agama utama ISIS, digambarkan oleh ISIS sebagai ideologi dan pemimpin spiritual. Pembenaran agama untuk mengubah "perempuan kafir" menjadi budak seks terdapat di dalam fatwa yang dirilis di dalam pamflet yang menguraikan justifikasi keagamaan dalam memperkosa dan memperbudak perempuan Yazidi. ${ }^{10}$

Pada paragraf ini penulis akan memaparkan genosida etnis Yazidi dikutip dari artikel jurnal karya Yessica Valerina Simamora yang berjudul "Beberapa Bentuk Kejahatan Genosida Terhadap Etnis Yazidi oleh Islamic State of Iraq and Syria (ISIS) Ditinjau dari Hukum Internasional". Dalam jurnal ini dijelaskan bahwa saat ini sekitar 300.000 orang etnis Yazidi telah mengungsi di wilayah Kurdistan sementara sisanya bertahan di Gunung Sinjar atau berpindah menuju Suriah dan Turki. Sekitar 5.000 orang Yazidi tewas ketika militan ISIS menyerbu Kota Sinjar. Berdasarkan laporan Perserikatan Bangsa-Bangsa yang dirilis pada tahun 2016 tersebut menjabarkan bahwa kejahatan ISIS secara sistematis menculik kaum Yazidi tersebut telah melanggar Konvensi Genosida tahun 1948.

"ISIS tidak menutupi keinginannya untuk menghancurkan Yazidi di Sinjar dan itu merupakan salah satu elemen yang membuat kami dapat menyimpulkan tindakan mereka sebagai genosida. Tentu, kami menganggap ini sebagai jalan menuju peradilan, untuk peradilan selanjutnya", tutur salah satu penyelidik, Carla del Pont, Kamis $(16 / 6){ }^{11}$

Dalam pernyataan tersebut, terlihat jelas bahwa Dewan HAM PBB berencana membawa kasus tersebut ke Pengadilan Kriminal Internasional (ICC) guna peradilan lebih lanjut. Walaupun PBB secara resmi menyatakan aksi ISIS terhadap etnis Yazidi sebagai genosida pada Juni 2016, praktik genosida tersebut masih terus berlangsung. ${ }^{12}$ Meski terus terdesak, ISIS belum surut dalam melakukan kebrutalan. Bahkan, ISIS dikabarkan membakar hidup-hidup 19 gadis Yazidi di Mosul, Irak karena mereka tidak ingin mematuhi perintah ISIS. $^{13}$

\footnotetext{
${ }^{10}$ Oriza, Op., Cit, hlm. 992.

${ }^{11}$ Reuters, 2016, ISIS Lakukan Genosida terhadap Kaum Yazidi Irak dan Suriah, diakses dalam https://www.cnnindonesia.com/internasional/20160616191516-120-138701/isis-lakukan-genosida-terhadapkaum-yazidi-irak-dan-suriah pada 11 Mei 2019.

12 DetikNews, 2015, PBB Serukan ISIS Diadili Mahkamah Internasional Atas Genosida, diakses dalam https://news.detik.com/internasional/d-2863943/pbb-serukan-isis-diadili-mahkamah-internasional-atas-genosida pada 11 Mei 2019.

${ }^{13}$ Yessica Valerina Simamora, 2018, "Beberapa Bentuk Kejahatan Genosida Terhadap Etnis Yazidi oleh Islamic State of Iraq and Syria (ISIS) Ditinjau dari Hukum Internasional”, Jurnal Universitas Sumatera Utara,
} ISSN 0216-5031

Copyright (C) 2018 Universitas Katolik Parahyangan 
Jurnal Sentris KSMPMI Vol. 2 - 2019

Beberapa perempuan Yazidi yang selamat dari ISIS banyak mengungkapkan kisah mereka ke publik. Salah satunya adalah korban pemerkosaan ISIS Nadia Murad, yang kini tinggal di Kanada sempat ikut mengerahkan aksi di alun-alun Yonge-Dundas pada 3 Agustus 2018, untuk memperingati serbuan ISIS terhadap etnis Yazidi. Nadia yang tidak memakai nama aslinya ini, ikut mengungkapkan kisahnya di panggung. Nadia menceritakan pengalaman pahitnya selama 2,5 tahun menjadi budak ISIS dan soal keluarganya yang masih disekap ISIS. Para pejuang ISIS membawa semua orang ke sekolah desa dan memisahkan pria dari wanita dan anak-anak.

Laki-laki dan perempuan lanjut usia dibunuh sementara para remaja putri dan anakanak dipaksa naik bus dan dibawa ke Mosul. Banyak anak laki-laki remaja dipaksa menjadi militan ISIS, sedangkan perempuan dan anak perempuan dijual sebagai budak. Murad dijual kepada seorang jihad yang memperkosa dan menghukumnya setiap hari. Akhirnya, dia bisa melarikan diri dan menemukan tempat perlindungan di Jerman. Murad datang ke Jerman pada tahun 2015 sebagai bagian dari program bagi perempuan korban kekerasaan. Di sana dia bertemu dengan Kanselir Jerman, Angela Merkel untuk mendiskusikan misinya menolong keluarganya dan korban kekejaman ISIS. ${ }^{14}$ Dia juga meminta bantuan pemerintah Kanada dan dunia internasional untuk menyelamatkan keluarganya. Pada bulan Oktober 2016, Menteri Imigrasi Kanada John McCallum menyatakan bahwa pemerintah federal akan segera melakukan tindakan untuk membawa pengungsi Yazidi ke Kanada, tetapi tidak disebutkan berapa jumlahnya. ${ }^{15}$

Menurut sebuah survei tahun 2016, mengatakan bahwa kebanyakan korban pengungsi Yazidi yang selamat mengalami trauma mendalam dan gangguan mental Post Traumatic Stress Disorder (PTSD). ${ }^{16}$ Walaupun beberapa telah hidup tenang di Kanada, tetapi dalam kehidupan sehari-hari mereka masih dibayangi oleh militan ISIS yang pernah menyekap mereka. Sebagai peraih hadiah Nobel Perdamaian 2018, Nadia Murad mengatakan para pemimpin dunia harus menerjemahkan rasa simpati mereka terhadap korban kekerasan seksual ke dalam langkah yang

hlm. 51. Diakses dalam

http://repositori.usu.ac.id/bitstream/handle/123456789/5186/120200258.pdf?sequence=1\&isAllowed=y pada 11 Mei 2019.

${ }^{14}$ Dw.com, 2018, Nobel Perdamaian Dipersembahkan untuk Pejuang Kekerasan terhadap Perempuan, diakses dalam https://www.dw.com/id/nobel-perdamaian-dipersembahkan-untuk-pejuang-kekerasan-terhadapperempuan/a-45778439 pada 11 Mei 2019.

15 TRT Melayu, 2017, Kanada Tingkatkan Jumlah Penerimaan Imigran di 2017, diakses dalam https://www.trt.net.tr/melayu/dunia/2016/11/01/kanada-tingkatkan-jumlah-penerimaan-imigran-di-2017-600778 pada 11 Mei 2019.

${ }^{16}$ Yessica Valerina Simamora, Op., Cit, hlm. 48.

ISSN 0216-5031

Copyright (C) 2018 Universitas Katolik Parahyangan 
Jurnal Sentris KSMPMI Vol. 2 - 2019

melawan para pelaku. Nadia, seorang perempuan yang menjadi Goodwill Ambassador pertama untuk Martabat Korban Perdagangan Manusia PBB.

"Faktanya bahwa satu-satunya hadiah di dunia yang dapat mengembalikan martabat kami adalah keadilan dan tuntutan terhadap para pelaku kejahatan," kata Murad dalam perayaan hadiah Nobel 2018, Senin (10/12). ${ }^{17}$

Sesuai dengan pernyataannya, Nadia bertekad untuk membawa ISIS ke pengadilan dan memberikan keadilan bagi orang-orang Yazidi. Cerita seperti Murad sering terjadi di kalangan Yazidi, meski banyak yang mengalami akhir yang kurang beruntung. Nadia telah menjadi simbol kelangsungan hidup orang-orang Yazidi karena dia bersedia memberi kesaksian secara terbuka dan berulang kali tentang pengalamannya yang mengerikan sebagai budak ISIS. Amal Clooney, pengacara HAM internasional, telah menangani Nadia Murad sebagai klien dan mereka bertekad untuk membawa pemimpin ISIS untuk diadili di meja Pengadilan Pidana Internasional yang didukung oleh pemerintah PBB dan Irak. ${ }^{18}$

Saat ini Clooney fokus mengumpulkan sebanyak mungkin bukti untuk persidangan. Dia mengajukan proposal untuk DK-PBB, agar membentuk sebuah badan bernama "Komisi ISIS". Komisi ini akan melibatkan pengiriman tim untuk menyelidiki kejahatan yang dilakukan oleh ISIS terhadap semua orang Irak, termasuk Sunni, Syiah, Kristen, dan Yazidi. Penyidik juga akan ditugaskan untuk mengumpulkan bukti dan mengidentifikasi tersangka ISIS yang dapat dihukum dengan sanksi keuangan. Nadia dan Clooney bukan yang pertama menjadi ujung tombak upaya untuk membawa kasus genosida ke ICC. ${ }^{19}$

Sebelumnya dua kelompok Yazidi, the Free Yezidi Foundation dan Yazda, menyerahkan sebuah laporan kepada jaksa ICC, Fatou Bensouda telah merinci kekejaman yang dilakukan oleh ISIS sejak Agustus 2014. Bensouda mengakui kejahatan berat yang telah dilakukan ISIS terhadap Yazidi di Suriah dan Irak, namun hanya mampu menyerukan kepada pihak internasional. Bensouda telah meminta komunitas internasional untuk bertindak karena dia tidak memiliki yurisdiksi untuk memproses kasus tersebut karena Irak dan Suriah bukan

\footnotetext{
${ }^{17}$ Lintar Satria dan Nur Aini, 2018, Nadia Murad Tuntut Keadilan Bagi Korban Kekerasan Seksual, diakses dalam https://www.republika.co.id/berita/internasional/eropa/18/12/10/pjj0b2382-nadia-murad-tuntut-keadilanbagi-korban-kekerasan-seksual pada 11 Mei 2019.

${ }^{18}$ KumparanWOMAN, 2019, Amal Clooney Kembali Menuntut Keadilan Korban Kekerasan Seksual ISIS, diakses dari https://kumparan.com/@kumparanwoman/amal-clooney-kembali-menuntut-keadilan-korbankekerasan-seksual-isis-1qxfyhtBEtc pada 11 Mei 2019.

${ }^{19}$ Yessica Valerina Simamora, Op., Cit, hlm. 62.
} 
Jurnal Sentris KSMPMI Vol. 2 - 2019

anggota ICC. ${ }^{20}$ Genosida Yazidi menyoroti masalah mendasar dengan hukum internasional yang perlu diperbaiki. Sampai saat ini, hanya ada sedikit penghalang untuk menghentikan kelompok teror seperti ISIS melakukan kejahatan seperti genosida, karena mereka tahu tindakan yudisial terhadap mereka kemungkinan akan dihentikan oleh hambatan jalan geopolitik dan tindakan lamban dari badan internasional. Maka dari itu, masyarakat internasional diharapkan memanfaatkan kondisi ini untuk mengambil tindakan pendampingan. Ribuan pengungsi Yazidi membutuhkan bantuan untuk akses ke rumah sakit, sekolah, dan pekerjaan, serta dukungan psikologis bagi ribuan wanita yang telah mengalami trauma dan kekerasan seksual.

Ditinjau dari teori feminisme, Nadia Murad berusaha memperjuangkan hak-hak etnis Yazidi, khususnya perempuan korban penyekapan dan pemerkosaan ISIS. Feminisme terutama ingin mendobrak pemikiran realisme yang sangat state-centric dan hanya berfokus pada kepentingan nasional dan kedaulatan sebagai alat untuk melegalkan perang. Misi penyelamatan etnis Yazidi tidak mudah karena pemerintah Irak tidak sepenuhnya memberikan perlindungan kepada mereka. Pemerintah Irak mengumumkan bahwa mereka tidak akan menerima anakanak yang dilahirkan oleh korban pemerkosaan para militan ISIS. Pengumuman ini seperti menjadi revisi dari pernyataan sebelumnya bahwa pemerintah Irak akan menerima semua korban ISIS yang selamat. ${ }^{21}$ Kurangnya dukungan dan perlindungan dari pemerintah Irak mendorong Nadia kini tampil menjadi sosok yang sangat kuat. Tidak mudah bagi seorang Nadia untuk keluar dari keterpurukannya di mana bayang-bayang kebengisan para teroris ISIS. Ia mengakui sempat putus asa, namun ia memberanikan diri 3untuk bersuara di hadapan dunia bahwa kekerasan dan kejahatan kemanusiaan yang dilakukan para teroris ISIS harus segera dihentikan.

Nadia dengan lantang bersuara untuk memperjuangkan hak-hak kaumnya untuk bisa lepas dari jerat kejahatan ISIS. Salah satunya di hadapan sidang PBB, ia menyentuh nurani masyarakat dunia untuk segera menghentikan kebejatan seraya menyelamatkan para perempuan, anak, dan anggota keluarga yang menjadi tawanan ISIS. Di dalam sambutannya ketika mendapatkan Nobel, ia berpesan untuk semua pihak berkomitmen untuk menghentikan penganiayaan terhadap minoritas, dan kekerasan seksual terhadap perempuan tidak boleh

20 Toby Sterling, 2015, Persecuted by Islamic State, Yazidis turn to ICC for justice, diakses dalam https://www.reuters.com/article/us-mideast-crisis-icc-yazidis-idUSKCNORO14G20150924 pada 11 Mei 2019.

21 Muhaimin, 2019, Yazidi Irak Tak Menerima Anak-anak Hasil Pemerkosaan ISIS, diakses dalam https://international.sindonews.com/read/1399847/43/yazidi-irak-tak-menerima-anak-anak-hasil-pemerkosaanisis-1556521374 pada 11 Mei 2019. 
Jurnal Sentris KSMPMI Vol. 2 - 2019

ditoleransi. Atas upaya dan keberaniannya, Nadia dianugerahi berbagai penghargaan dunia seperti Nobel Perdamaian 2018, Vaclav Havel Human Rights Prize, Sakharov Prize, dan Clinton Global Citizen Award and the Peace Prize dari Perserikatan Bangsa-Bangsa (PBB) di Spanyol. ${ }^{22}$ Dia telah dipuji oleh para politisi dan didukung oleh para selebritas terutama Amal Clooney, dan berhasil menerbitkan sebuah buku yang berjudul The Last Girl: My Story of Captivity and My Fight Against the Islamic State.

Dalam bukunya, Nadia menceritakan kebrutalan para anggota ISIS yang memperkosanya sampai tak sadarkan diri. Nadia ditangkap saat desanya di Irak diserang kelompok radikal tersebut pada tahun 2014 dan ditawan menjadi budak seks ISIS. Lima dari delapan saudara laki-lakinya berserta ibunya dibunuh. Selama jadi tawanan, Nadia diperbudak, berulang kali diperkosa, dan bahkan diperintahkan untuk pindah agama. Foto kartu identitasnya dibagikan di antara para militan ISIS untuk dijadikan ancaman agar dia tidak bisa melarikan diri. Dalam bukunya tersebut, dia menjelaskan bagaimana dia mencoba melarikan diri dengan merangkak keluar dari jendela namun tertangkap oleh seorang penjaga. Namun, dia tidak mudah menyerah untuk tetap mencoba untuk melarikan diri dan berhasil keluar dari tempat tersebut untuk meminta bantuan. Nadia menyatakan bahwa kisah ini adalah senjata terbaik yang dia miliki untuk melawan terorisme, dan Nadia akan menggunakannya sampai para teroris tersebut diadili. ${ }^{23}$

Kasus penyekapan dan pemerkosaan oleh ISIS ini patut menjadi perhatian keamanan internasional. Semua pihak harus menghukum pelakunya, termasuk menghentikan ISIS. Nadia beserta korban ISIS lainnya telah berulang kali menceritakan kisahnya, berharap bantuan akan menyusul. Mereka telah membuat perhitungan sederhana, menyatakan bahwa menceritakan kisah mereka akan membantu keluarga mereka. Meskipun ada banyak korban, mereka tetap bertahan. ${ }^{24}$ Tapi alih-alih kisah kepahlawanan dalam melarikan diri dari penawanan ISIS, fokus media bergeser ke bentuk-bentuk penyiksaan seksual yang telah mereka alami. Sebagai seorang feminis, penulis mendapati hal ini melemahkan stigma perlawanan perempuan. Selama

22 CNN Indonesia, 2018, Cerita Nadia, Budak Seks ISIS Peraih Nobel Perdamaian, diakses dalam https://www.cnnindonesia.com/internasional/20181006131351-120-336243/cerita-nadia-budak-seks-isis-peraihnobel-perdamaian pada 11 Mei 2019.

${ }^{23}$ Muhaimin, 2017, Wanita Yazidi Bukukan Kisah Mengerikan Selama Jadi Budak Seks ISIS, diakses dalam https://international.sindonews.com/read/1258893/43/wanita-yazidi-bukukan-kisah-mengerikan-selama-jadibudak-seks-isis-1511149397 pada 11 Mei 2019.

${ }^{24}$ Lara Whyte, 2018, Nadia Murad may have won the Nobel peace prize, but the world failed her Yazidi people, diakses dalam https://www.opendemocracy.net/en/5050/nadia-murad-won-nobel-world-failed-her-yazidipeople/ pada 11 Mei 2019.

ISSN 0216-5031

Copyright (C) 2018 Universitas Katolik Parahyangan 
Jurnal Sentris KSMPMI Vol. 2 - 2019

bertahun-tahun, tampaknya dunia tidak peduli dengan kisah Nadia, sementara ribuan masyarakat lainnya menyukainya. Butuh waktu dua tahun bagi Sekretaris Negara saat itu, John Kerry untuk mendeklarasikan kejahatan terhadap Yazidi, Kristen, dan genosida Muslim Syiah, serta pelanggaran terhadap PBB. Ribuan Yazidi masih hilang, termasuk setidaknya 1.300 perempuan dan anak-anak, dan pertanyaan tentang bagaimana meminta pertanggungjawaban ISIS atas kejahatannya yang tak terkatakan tetap tidak terjawab. Nadia adalah suara kesepian dalam perang melawan genosida ISIS.

Di era \#MeToo, kaum feminis benar-benar peduli tentang wanita yang didengar. Tampaknya Nadia juga bersama mereka. Harapan Nadia adalah bahwa semua wanita yang berbicara tentang kisah-kisah kekerasan seksual mereka dapat didengar dan diterima, bahwa suara mereka didengar sehingga mereka merasa aman. Mendengarkan seorang pemenang Hadiah Nobel Perdamaian yang misinya adalah untuk menghidupkan kembali kehidupan setelah dihancurkan oleh kekerasan seksual dan perang adalah hal yang luar biasa, walaupun banyak rintangan yang harus dilalui. Namun, hal tersebut adalah tugas kita sebagai feminis untuk melihat melampaui diri kita sendiri dan menyadari bahwa pertarungan Nadia adalah perjuangan kita juga. ${ }^{25}$

\section{Kesimpulan}

Feminisme sebagai salah satu cabang dan perspektif ilmu hubungan internasional karena ide-ide tentang negara dan yang berorientasi negara telah mengesampingkan masalah gender yang semakin kompleks dalam konstelasi global. Kompleksitas tersebut dapat terlihat dari semakin berpengaruhnya peran perempuan dalam konteks dan konstelasi global. Perempuan mulai mengambil alih posisi-posisi penting baik di tingkat negara maupun tingkat organisasi internasional. Pemikiran feminisme dalam Hubungan Internasional beranggapan bahwa telah terjadi diskriminasi atas keberadaan perempuan dalam politik internasional yang disebabkan oleh beberapa faktor sehingga membuat mereka dipandang tidak memiliki peranan penting.

ISIS telah menggunakan kekerasan seksual, pemerkosaan, perbudakan seks, perkawinan paksa, penculikan, dan pemaksaan agama sebagai metode yang tersebar luas dan

\footnotetext{
${ }^{25}$ Kelsey Bolar, 2018, A Rape Survivor Just Won the Nobel Peace Prize. 'Feminists' Are Nowhere to Be Found diakses dalam https://www.dailysignal.com/2018/10/12/a-rape-survivor-just-won-the-nobel-peace-prizefeminists-are-nowhere-to-be-found/ pada 11 Mei 2019.
}

ISSN 0216-5031

Copyright (? 2018 Universitas Katolik Parahyangan 
Jurnal Sentris KSMPMI Vol. 2 - 2019

sistematis untuk menghacurkan kelompok etnis Yazidi. Penargetan perempuan dan anak perempuan melalui kekerasan seksual dan taktik gender lainnya harus dipertimbangkan terutama sebagai masalah hak asasi manusia perempuan, dengan budaya patriarki sebagai landasan dasarnya. Namun, kebencian terhadap wanita dapat berkaitan dengan kebencian etnis dan agama untuk menghasilkan kekerasan seksual yang digunakan dengan maksud untuk menghilangkan kelompok tertentu. Kasus perbudakan ISIS ini merupakan masalah keamanan internasional yang patut diselesaikan. Nadia Murad merupakan salah satu aktivis wanita yang ingin mengangkat derajat hak-hak kaumnya, terutama perempuan Yazidi dengan turut serta mengkampanyekan berbagai aksi sosial melawan ketiranian ISIS.

Aksi Nadia ini menjadi sorotan dunia karena ia mampu berdiri tegar setelah melewati penyekapan dan perbudakan ISIS, serta berhasil mendapatkan Nobel Perdamaian pada tahun 2018 yang lalu. Munculnya aktivis perempuan seperti Nadia ini, salah satunya disebabkan oleh kurangnya dukungan dan perlindungan dari pemerintah negara asalnya dalam menangani kasus tersebut. Akibatnya, gerakan feminisme terus bermunculan karena mereka beranggapan bahwa negara sudah tidak mampu menangani kasus diskriminasi dan kekerasan terhadap perempuan. Penjelasan di atas menunjukkan bahwa menggunakan feminsime sebagai kategori analisis dalam studi hubungan internasional penting karena mampu menawarkan cara pandang baru agar kita tidak hanya terpaku pada permasalahan negara saja melainkan permasalahan diskiriminasi dan kekerasan perempuan di dunia. 


\section{Daftar Pustaka}

\section{Buku}

Ashari, Khasan. Kamus Hubungan Internasional. Bandung: Nuansa Cendekia, 2015.

\section{Jurnal}

Azizah, Nur. "Feminisme dalam Hubungan Internasional." Jurnal Diskusi Feminisme dalam Hubungan Internasional (2013). http://hi.umy.ac.id/wp-content/uploads/2013/02/NurAzizah-Feminisme-dalam-HI.pdf pada 11 Mei 2019.

Ardiyanti, Oriza. "Perbudakan ISIS terhadap Perempuan Etnis Yazidi di Irak sebagai Kejahatan terhadap Kemanusiaan dalam Konflik Bersenjata.” Jurnal Universitas Diponegoro (2019). https://ejournal3.undip.ac.id/index.php/jihi/article/viewFile/22736/20789 pada 11 Mei 2019.

Nuryati. “Feminisme dalam Kepemimpinan.” Jurnal Universitas Islam Negeri Raden Fatah Palembang (2015).

http://jurnal.radenfatah.ac.id/index.php/istinbath/article/download/792/700/ pada 11 Mei 2019.

Simamora, Yessica Valerina. "Beberapa Bentuk Kejahatan Genosida Terhadap Etnis Yazidi oleh Islamic State of Iraq and Syria (ISIS) Ditinjau dari Hukum Internasional.” Jurnal Universitas Sumatera Utara (2018).

http://repositori.usu.ac.id/bitstream/handle/123456789/5186/120200258.pdf?sequence =1\&isAllowed=y pada 11 Mei 2019 .

\section{Berita}

Bolar, Kelsey. A Rape Survivor Just Won the Nobel Peace Prize. 'Feminists' Are Nowhere to Be Found, 2018. https://www.dailysignal.com/2018/10/12/a-rape-survivor-just-wonthe-nobel-peace-prize-feminists-are-nowhere-to-be-found/ pada 11 Mei 2019.

Christiastuti, Novi. Ribuan Wanitia Yazidi Masih Jadi Budak Seks ISIS, 2018. https://news.detik.com/internasional/d-4149753/ribuan-wanita-yazidi-masih-jadibudak-seks-isis pada 11 Mei 2019.

CNN Indonesia. Cerita Nadia, Budak Seks ISIS Peraih Nobel Perdamaian, 2018. https://www.cnnindonesia.com/internasional/20181006131351-120-336243/ceritanadia-budak-seks-isis-peraih-nobel-perdamaian pada 11 Mei 2019. 
Jurnal Sentris KSMPMI Vol. 2 - 2019

DetikNews. PBB Serukan ISIS Diadili Mahkamah Internasional Atas Genosida, 2015. Diakses dalam https://news.detik.com/internasional/d-2863943/pbb-serukan-isis-diadilimahkamah-internasional-atas-genosida pada 11 Mei 2019.

Dw.com. Nobel Perdamaian Dipersembahkan untuk Pejuang Kekerasan terhadap Perempuan, 2018. Diakses dalam https://www.dw.com/id/nobel-perdamaiandipersembahkan-untuk-pejuang-kekerasan-terhadap-perempuan/a-45778439 pada 11 Mei 2019.

Fadhil, Haris. 2018. Kekejaman ISIS Jadikan Ribuan Wanita Yazidi Budak Seks. Diakses dalam https://news.detik.com/internasional/d-4150014/kekejaman-isis-jadikan-ribuanwanita-yazidi-budak-seks pada 11 Mei 2019.

KumparanWOMAN. Amal Clooney Kembali Menuntut Keadilan Korban Kekerasan Seksual ISIS, 2019. Diakses dari https://kumparan.com/@kumparanwoman/amal-clooneykembali-menuntut-keadilan-korban-kekerasan-seksual-isis-1qxfyhtBEtc pada 11 Mei 2019.

Muhaimin. Yazidi Irak Tak Menerima Anak-anak Hasil Pemerkosaan ISIS, 2019. https://international.sindonews.com/read/1399847/43/yazidi-irak-tak-menerima-anakanak-hasil-pemerkosaan-isis-1556521374 pada 11 Mei 2019.

Muhaimin. Wanita Yazidi Bukukan Kisah Mengerikan Selama Jadi Budak Seks ISIS, 2017. https://international.sindonews.com/read/1258893/43/wanita-yazidi-bukukan-kisahmengerikan-selama-jadi-budak-seks-isis-1511149397 pada 11 Mei 2019.

Nursya'bani, Fira dan Esthi Maharani. Perempuan Yazidi Rencanakan Serangan Balas Dendam untuk ISIS, 2016. https://www.republika.co.id/berita/internasional/global/16/11/15/ogns8s335perempuan-yazidi-rencanakan-serangan-balas-dendam-untuk-isis pada 11 Mei 2019.

Reuters. ISIS Lakukan Genosida terhadap Kaum Yazidi Irak dan Suriah, 2016. Diakses dalam https://www.cnnindonesia.com/internasional/20160616191516-120-138701/isislakukan-genosida-terhadap-kaum-yazidi-irak-dan-suriah pada 11 Mei 2019.

Satria, Lintar dan Nur Aini, Nadia Murad Tuntut Keadilan Bagi Korban Kekerasan Seksual, 2018. https://www.republika.co.id/berita/internasional/eropa/18/12/10/pjj0b2382nadia-murad-tuntut-keadilan-bagi-korban-kekerasan-seksual pada 11 Mei 2019.

Sterling, Toby. Persecuted by Islamic State, Yazidis turn to ICC for justice, 2015. https://www.reuters.com/article/us-mideast-crisis-icc-yazidisidUSKCNORO14G20150924 pada 11 Mei 2019. 
Jurnal Sentris KSMPMI Vol. 2 - 2019

TRT Melayu. Kanada Tingkatkan Jumlah Penerimaan Imigran di 2017, 2017. https://www.trt.net.tr/melayu/dunia/2016/11/01/kanada-tingkatkan-jumlahpenerimaan-imigran-di-2017-600778 pada 11 Mei 2019.

Whyte, Lara. Nadia Murad may have won the Nobel peace prize, but the world failed her Yazidi people, 2018. https://www.opendemocracy.net/en/5050/nadia-murad-won-nobelworld-failed-her-yazidi-people/ pada 11 Mei 2019. 